\title{
Ethosociological Studies of the Black-winged Stilt Himantopus himantopus himantopus I. Ethogram of the Agonistic Behaviours
}

\author{
Tamaki Kitagawa*
}

\begin{abstract}
Agonistic behaviour in the Black-winged Stilt, Himantopus himantopus himantopus, was observed at Ichikawa City, Chiba Prefecture, from April 1985 to December 1987. For convenience, two components, postures and calls, were described separately. Agonistic postures appeared in coactions between conspecifics or with other animals and were classified into nine categories: (1) alert with five types; (2) leaning body; (3) lowering head; (4) repelling water; (5) patrolling; (6) irrelevant behaviours with nine types; (7) attacking with eight types; (8) avoiding with six types; and (9) diversionary display with two types. Agonistic calls were classified into alarm calls, snake alerting calls, aggressive calls, and diversionary calls. These postures and calls are described in detail and situations at which they were observed are described.
\end{abstract}

\section{Introduction}

Among various groups of birds in the Order Charadriiformes, the Family Recurvirostridae with three genera, Recurvirostra (four species, $R$. americana, $R$. novaehollandiae, $R$. andina, $R$. avosetta), Cladorhynchus (monobasic, $C$. leucocephalus), and Himantopus (one polytypic species, $H$. himantopus) is outstanding by extremely long legs, long bills, slim bodies and long and pointed wings. $H$. himantopus, which is classified in five subspecies, breeds along shores of brackish and freshwater bodies in various areas of the both hemispheres even in some remote Oceanic islands such as Hawaii and Galapagos, although breeding is not recorded from Antarctica and the Arctic zones (Cramp and Simmons 1983). Some aspects of its biology were recorded by Yeates (1941, breeding habits), Glutz von Blotzheim et al. (1977, breeding habits and behaviours), Goriup (1982, general behaviours), and especially by Hamilton (1975, general behaviours), but many aspects are still only superficially explored, necessitating more detailed studies. The type subspecies $H$. h. himantopus or Black-winged Stilt is distributed Eurasia and Africa, known from southern Europe eastward to Mongolia and southward to South Africa, Madagascar, and Sri Lanka. Its breeding is recorded from northwestern Africa, and Eurasia (Cramp and Simmons 1983). In Japan this subspecies had been known until recently as an accidental visitor. Its breeding was first recorded at a reclaimed shore of Nabeta, Aichi Prefecture in 1975 and 1976 (Hasuo 1982). In 1978 one pair bred at a reclaimed shore of Yazu in Narashino City, and in 1979, another pair bred at the same area and one more pair at a reclaimed shore of Makuhari in Narashino City, all in Chiba Prefecture. Since 1979 more than one pair have bred every year at the Shinhama Imperial Preserve in Ichikawa City, Chiba Prefecture, and have overwintered at Gyotoku Sanctu-

Received 20 September 1988; accepted 26 November 1988

* Ichikawa High School, 4-1-1 Higashi-Sugano, Ichikawa, Chiba Pref. 272. 


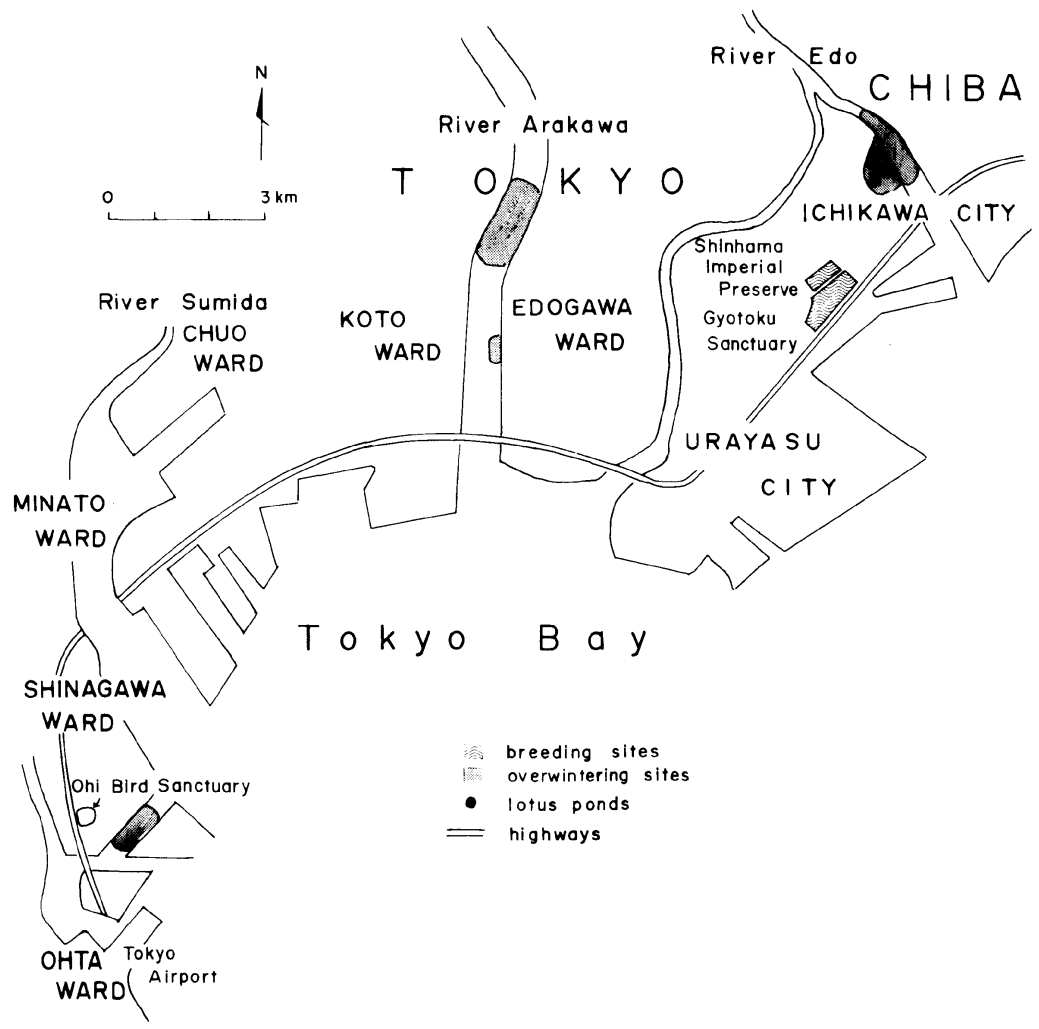

Fig. 1. Locations of breeding and overwintering areas studied.

ary and the vicinity (Kunimatsu 1979, Hasuo 1982).

Since 1985 I began to elucidate the ethology, socilogy and ecology of $H$. h. himantopus through field observations. This paper represents the first report of my serial studies on this bird.

Behavioural patterns of $H$. himantopus (henceforth cited by the generic name unless distinction is necessary) have been studied by several authors. However, most previous works have been restricted to breeding behaviours (Witherby et al. 1940, Staton 1945) except for brief notes on social behaviours (Glutz von Blotzheim et al. 1977, Goriup 1982) and a detailed comparative study on behaviours of the Nearctic subspecies, the Blacknecked Stilt, H. h. mexicanus, by Hamilton (1975). Few precise studies of agonistic behaviours of Himantopus have been made in reference to associated movements or situations under which the concerned behaviour patterns were frequently released. This paper describes the agonistic behaviours based upon observations of territorial defence in both breeding and nonbreeding seasons, other intraspecific interactions, and movements elicited by predators and competitors. Discussion of the results will be given in a separate paper. Also ethogram of other behaviours such as maintenance behaviours, reproductive behaviours and parental care will be described elsewhere. 


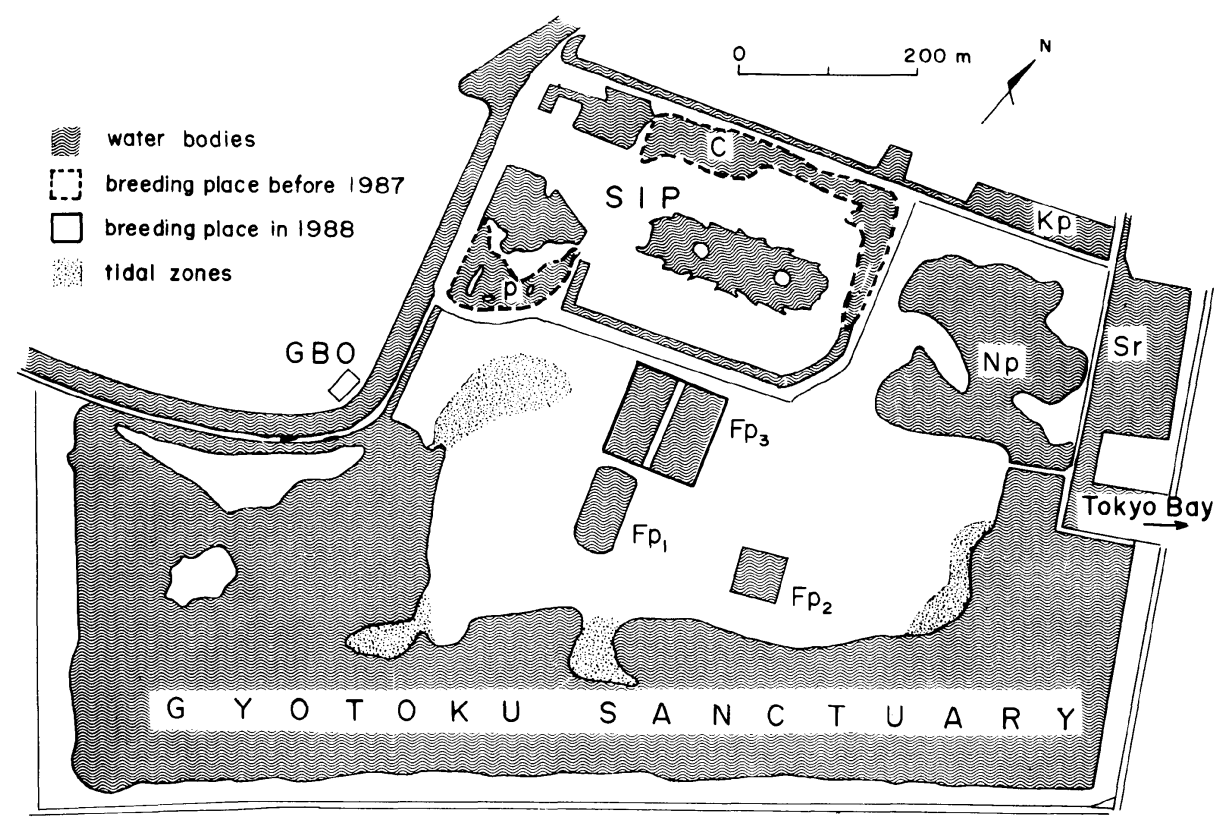

Fig. 2. Locations of Gyotoku Sanctuary and Shinhama Imperial Preserve. SIP, Shinhama Imperial Preserve; p, pond in SIP; c, canal; GBO, Gyotoku Bird Observatory; Sr, Sewage reservoir; $\mathrm{Np}$, North pond; $\mathrm{Kp}$, Kingyo pond; $\mathrm{Fp}_{\mathbf{1}-3}$, freshwater ponds.

\section{Study Areas}

The study was carried out in Ichikawa City, $139^{\circ} 55^{\prime} \mathrm{E}, 35^{\circ} 40^{\prime} \mathrm{N}$, Chiba Prefecture (Fig. 1). The breeding sites are shores of a shallow pond $(100 \mathrm{~m} \times 100 \mathrm{~m})$ in Shinhama Imperial Preserve (Fig. 2, p) and a part $(50 \mathrm{~m} \times 450 \mathrm{~m})$ of a shallow canal encircling the preserve (Fig. 2,c), into which salt water is poured (Fig. 2). These shores are covered with Phragmites communis, and partly surrounded with clumps of trees, Pleioblastus simonii, Machilus thunbergii, Pinus thunbergii, Pittosporum tobira, Celtis sinensis var., etc. In 1988 breeding sites moved to two newly made ponds (each ca. $50 \mathrm{~m} \times 90 \mathrm{~m}$ ) in an open land predominated by Solidago altissima within Gyotoku Sanctuary, into which ditch water is poured (Fig. 2, $\mathrm{Fp}_{3}$ ). In autumn many groups of various compositions, pairs with or without yearlings, uniparental families, yearling pairs and solitary birds, temporarily gathered at the North pond in Gyotoku Sanctuary contiguous to Shinhama Imperial Preserve (Fig. 2). The North pond is ca. $2.9 \mathrm{~km}^{2}$, surrounded with Phragmites communis. Overwintering places are at shores along the lower reaches of the River Edo (Fig. 1), where broad muddy beaches appear at low tide, and lotus ponds scattered within the wasteland nerby (Fig. 1) at about $3 \mathrm{~km}$ distant from Shinhama Imperial Preserve, and the shores of the River Arakawa (Fig. 1), where narrow sandy beaches appear at low tide, at about $6 \mathrm{~km}$ distant from Shinhama Imperial Preserve. 


\section{Methods}

I observed the birds using a binocular telescope $(\times 10)$ and a high magnification telescope $(\times 25 \sim \times 60)$. The birds could be identified individually by a number of features: feather colouration, deformities or wounds on legs and some other morphological peculiarities. However, these features were useful only for peculiar birds, e.g. birds in nesting or overwintering territories, not always for those in large flocks because accurate individual recognition was difficult in such cases, or not for those observed intermittently as colouration changed by moulting. Several chicks were colour-banded two to three weeks after hatching. Identification of sexes was easy for sexual dimorphism in plumage colouration of wings and back, greenish-black in males whereas brown in females.

Observations were made approximately from 1300 to 1800 , every three to five days per week from April 1985 to December 1987. Behavioural patterns were recorded together with circumstances at which the respective patterns were released. Besides field recording, many postures and movements were photographed by $35 \mathrm{~mm}$ format cameras with $500 \mathrm{~mm}$ telephoto lens. Accompanied figures were redrawn from these photos.

In the nonbreeding season on each observation day I first censused the number of Himantopus along the River Edo by checking individually recognized birds. Then birds or families checked were observed each for about $30 \mathrm{~min}$ to $1 \mathrm{~h}$ before checking the next one. In the breeding season the birds were so cautious at nesting sites that observations were made from a one-person-blind set in a bamboo bush. Call notes were represented by means of letter combinations.

\section{Results}

Agonistic behaviours occupy a part of the entire ethogram which is now under preparation and consists of the following parts: Resting, sleeping, comfort movement, locomotion, food intake, defecation, agonistic behaviour, reproductive behaviour, and parental care.

Table 1 shows the relative frequency of appearance (total $=615$ cases) of other animals which elicited agonistic behaviours from Himantopus in the course of observations. Actual frequency varied according to season and year. The bird exhibited agonistic behaviours toward other animals mostly in the breeding season, especially in the incubating and parental care period, while with low frequencies in the nonbreeding season. Table 2 shows observed cases of each agonistic postures and calls at invasions of other animals (Table 1, A, B, and C) and at invasion of conspecifics.

The descriptions are conveniently divided in two parts: Postures (A) and calls (B).

\section{A. Behavioural postures}

A.1. Alert (Fig. 3): Five types are recognized. These appear each at different situations and possibly caused by different underlying mechanisms. All are exhibited by both sexes, and usually accompanied by alarm call (B.1.). 


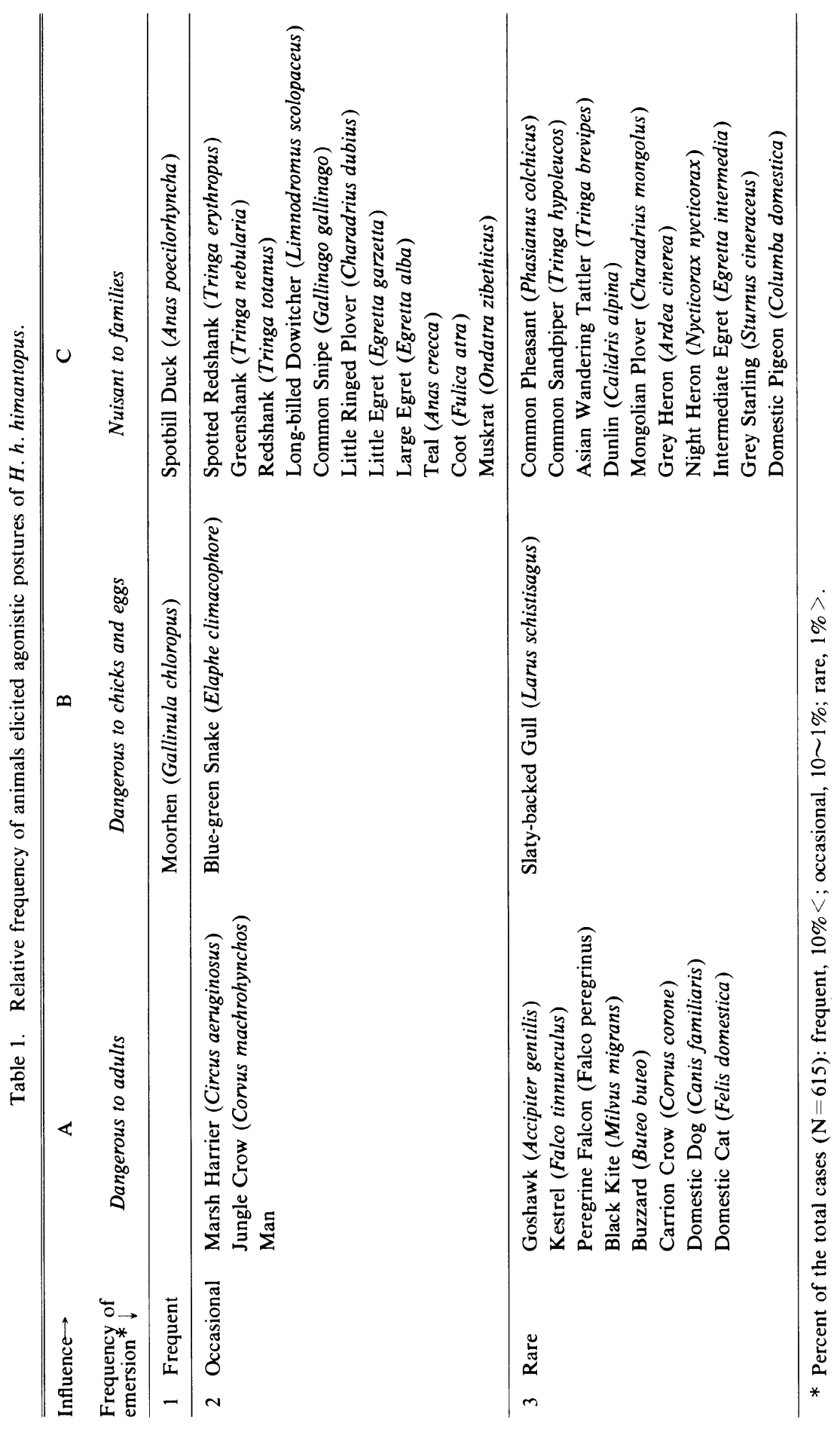




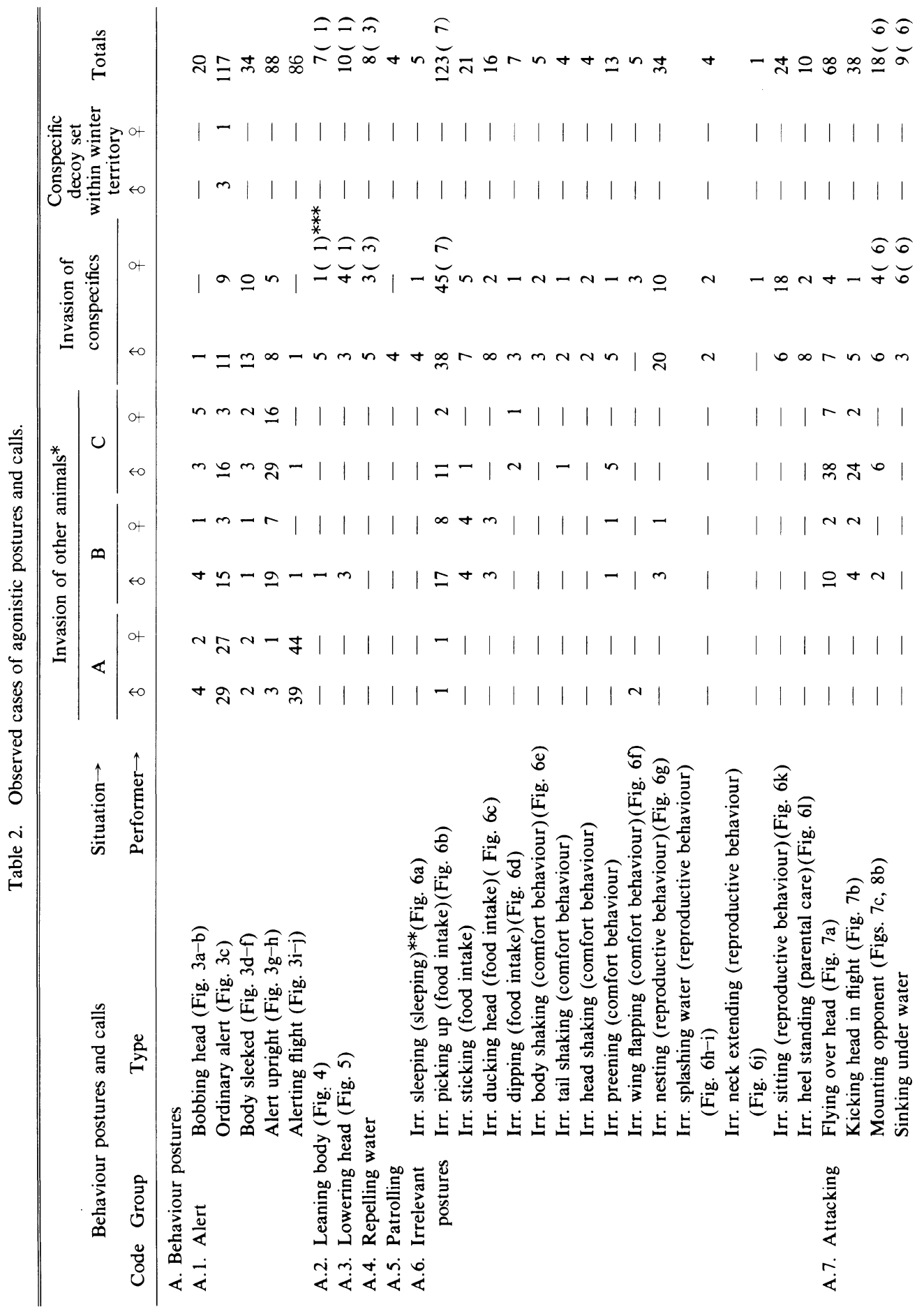




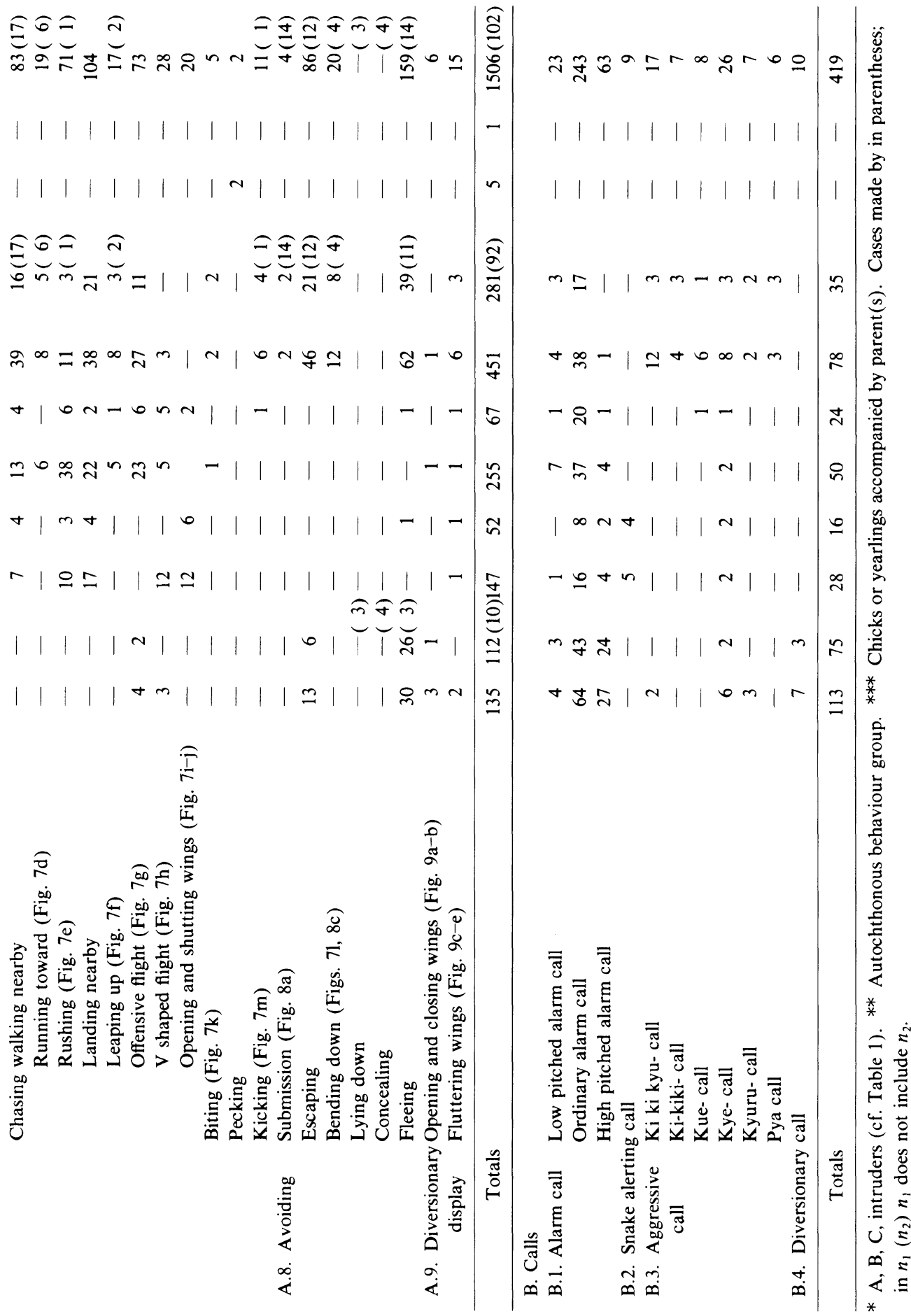



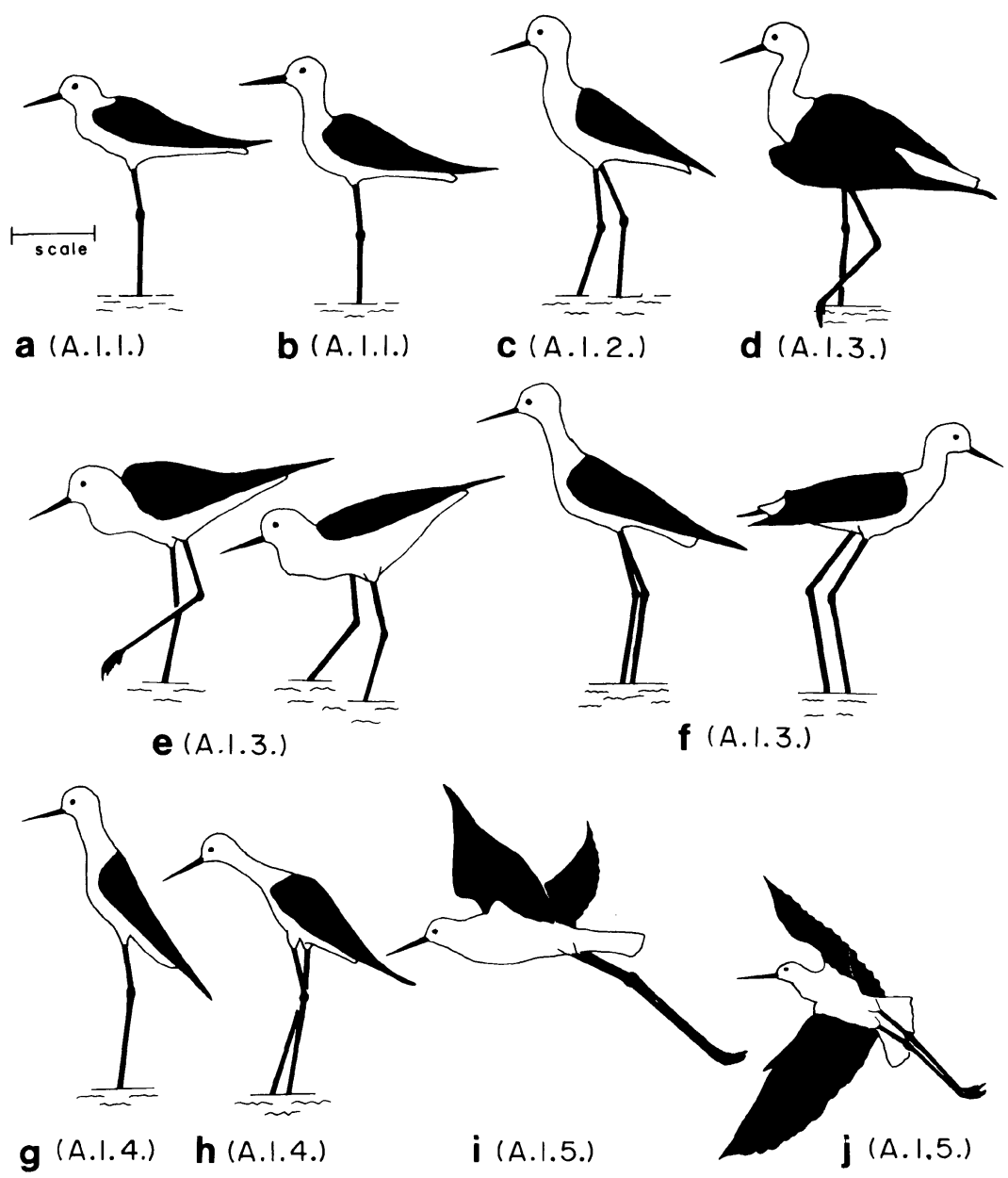

Fig. 3. Alert postures. a-b, bobbing head; c, ordinary alert; d, body sleeked with drooping wings; e, body sleeked standing side by side; f, body sleeked looking the other way; $\mathrm{g}-\mathrm{h}$, alert upright; $i-j$, alerting flight. (scale $10 \mathrm{~cm}$ ).

A.1.1 Bobbing head (Fig. 3a-b): Feathers normal or rarely sleeked, trunk held horizontally or rarely obliquely up, and head repeatedly bobbed several centimetres up and down.

The bird performs bobbing head toward conspecific invaders and any suspicious animals such as Grey Heron, Moorhen, Night Heron, Common Snipe and man, which appeared in the nesting territory or approached the nest or the chicks.

Bobbing head is occasionally shown during neck- retracted-resting (in comfort postures, unpubl.), body sleeked (A.1.3., Fig. 3d-f), and alert upright (A.1.4., Fig. 3 g-h), and sometimes followed by other alert postures (A.1., Fig. 3) or chasing (A.7.5., Fig. 7, $d-j)$. 


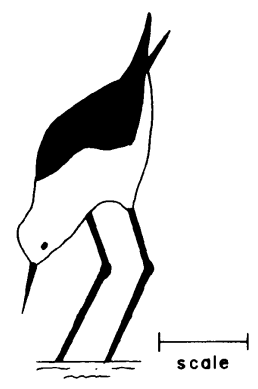

Fig. 4. Leaning body.

$(A .2$.

A.1.2. Ordinary alert (Fig. 3c): Feathers sleeked, trunk held slightly obliquely up, neck extended upward, and head kept high.

Ordinary alert is frequently exhibited when recognizing hetero- and conspecific invaders, or sometimes after driving these invaders out of the nesting territory. Ordinary alert is usually accompanied by alarm call (B.1.).

A.1.3. Body sleeked (Fig. 3d-f): Similar to upright posture described by Hamilton (1975). Feathers sleeked, trunk held obliquely up, and head kept high.

Body sleeked is exhibited mostly between territory owners and conspecific invaders at the territorial borders or within the territory. The owner and invader stand side by side (Fig. 3e), or looking the other way (Fig. 3f), sometimes still for a while, or walk slowly with this posture. The birds sometimes hold out both wings very slightly from flanks, rarely drooping one wing or both slightly (Fig. 3d). At prolonged conflicts, the birds bent legs slightly, trunk a little obliquely down, and head kept slightly high (Fig. 3e). In the last case this posture sometimes shifts to irrelevant crouching (A.6.9., Fig. 6k-1) or lowering head (A.3., Fig. 5). Body sleeked is sometimes preceded or followed by alert upright (A.1.4., Fig. 3g-h), or followed by irrelevant picking up (A.6.2.1., Fig. 6b), and leaning body (A.2., Fig. 4), lowering head (A3., Fig. 5), and rarely accompanied by bobbing head (A.1.1., Fig. 3a-b).

A.1.4. Alert upright (Fig. $3 \mathrm{~g}-\mathrm{h}$ ): Same as giraffe posture described by Hamilton (1975). Feathers fairly sleeked, trunk held fairly obliquely up, head kept highest, and neck extended obliquely up.

The bird occasionally walks slowly with this posture toward the opponent or pays attention to it in standstill. Alert upright is rarely accompanied by bobbing head (A.1.1., Fig. $3 \mathrm{a}-\mathrm{b}$ ), or the bird rarely runs toward the opponent with this posture. Alert upright is exhibited especially in the breeding season between territory owners and conspecific invaders during conflict, or toward other species approaching the nest or chicks or crossing the territory, such as Moorhen, Spotbill-duck, Teal, Common Pheasant, Common Snipe, Long-billed Dowitcher, Blue-green Snake and man.

A.1.5. Alerting flight(Fig. $3 \mathrm{i}-\mathrm{j}$ ): Comparable with ftying postures (unpubl.) or offensive flight (A.7.5.6., Fig. 7g) in chasing postures (A.7.5.) but legs slightly dangled and neck kept slightly down.

If an animal dangerous for eggs or chicks such as Carrion Crow, Jungle Crow, 


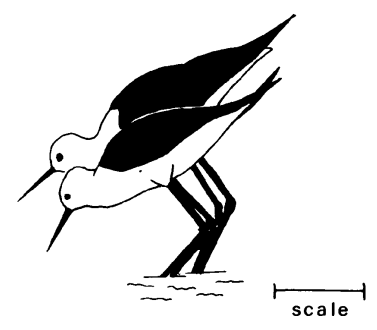

a (A.3.)

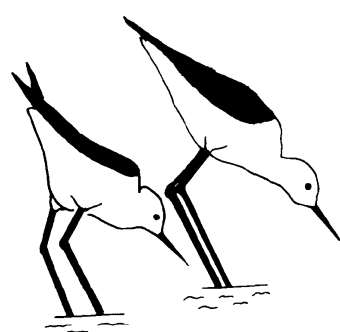

b (A.3.)

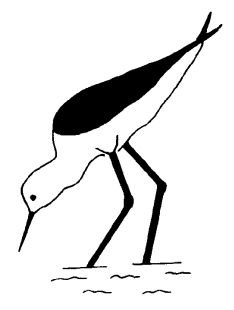

Fig. 5. Lowering head. a, lowering head standing side by side; $b$, lowering head standing face to face. $($ scale $=10 \mathrm{~cm})$.

Buzzard, Slaty-backed Gull and Marsh Harrier flies over the nesting territory or man enters there, the owner flies around, uttering high pitched alarm call (B.1.3.), aggressive call (B.3.) or ordinary alarm call (B.1.2.). Neighbouring individuals usually join in this flight. Alerting flight is usually preceded or followed by offensive flight (A.7.5.6., Fig. 7g) in chasing postures (A.7.5.).

A.2. Leaning body (Fig. 4): Feathers sleeked, trunk held fairly down, or horizontally, or rarely obliquely up, and leaned toward the opponent. The collateral wing occasionally slightly drooped downward and the other wing held perkly slightly, or rarely moved inversely. Legs sometimes slightly bent.

Leaning body sometimes occurs during irrelevant picking up (A.6.2.1., Fig. 6b), and body sleeked (A.1.3., Fig. 3d-f). Leaning body is exhibited by both sexes and is occasionally performed when the territory owner and invader, or two neighbouring families, get close together at the territorial border. Once a bird performed leaning body when ready to be mounted back (cf. A.7.3., Figs. 7c, 8b) by others. Occasionally, Leaning body is exhibited between pairs during showing nest spot (in nest building postures, unpubl.), but once the last year young performed this posture toward the mother on the nest when a female performed showing nest spot. A female usually exhibits leaning body during splashing water (in copulation postures, unpubl.)

A.3. Lowering head (Fig. 5): Feathers fairly sleeked, trunk held fairly downward, and head kept lowest.

Usually two birds, occasionally all members of two families, perform this posture standing side by side (Fig. 5a), face to face (Fig. 5b), or looking the other way and still for a while with legs sometimes slightly bent. This posture is very rarely accompanied by a specific call "pya! pya! pya !......", and sometimes followed by irrelevant crouching (A. 6.9., Fig, 6k-1), interposed by irrelevant picking up (A.6.2.1., Fig. 6b), and leaping up (A. 7.5.5., Fig. 7f). Lowering head is exhibited by both sexes and usualy at opposition between territory owners and invaders at the territorial border and rarely toward the moorhen approaching the nest.

A.4. Repelling water: Feathers slightly sleeked. Comparable with lowering head (A.3., Fig. 5) or touching water surface before preening postures, unpubl.).

With this posture the bird repels water or pecks the water-surface quickly. Repelling 
water is exhibited by both sexes and performed by the territory owner toward invaders or reversely, mostly during chasing postures, such as walking nearby (A.7.5.1.). Irrelevant preening (A.6.4.) and irrelevant head shaking (A.6.3.3.) sometimes occur during repelling water.

A.5. Patrolling: Identical to slow walking (in locomotion postures, unpubl.). Feathers normal, head kept fairly high, and trunk held nearly horizontally. Similar to foraging (in food intake postures, unpubl.), but not accompanied by feeding posture.

Patrolling was exhibited only by a particular male several times. With this posture and in a slow walking this male frequented a place within his nesting territory which was invaded frequently.

A.6. Irrelevant postures (Fig. 6): Nine kinds of irrelevant postures were recognized usually at close conflicts between territory owners and conspecific invaders, during fighting between families, and in driving away heterospecific invaders in the nesting territory, such as Spotbill Duck, Teal, Little Egret, Moorhen, Common Pheasant, Asian Wandering Tattler, Muskrat and man. All exhibited by both sexes, except for irrelevant neck extending (A.6.8., Fig. 6j) which was only once performed by a female. However, some cases require more precise observations, e.g. irrelevant sleeping, irrelevant shaking, irrelevant wing flapping, and irrelevant neck extending.

A.6.1. Irrelevant sleeping (Fig. 6a): Observed only several times. Just after the male owner of the winter territory approached a clay decoy set within there and pecked it, the bird exhibited irrelevant sleeping for about ten minutes. The posture was not distinguished from actual sleeping (unpubl.).

A.6.2. Irrelevant food intake: Four distinct types are recognized. All usually accompanied by low pitched or ordinary alarm call (B.1.1., B.1.2.) and sometimes with actual food intake.

A.6.2.1. Irrelevant picking up (Fig. 6b): Most frequent among irrelevant postures. Comparable with picking up (in food intake postures, unpubl.), but feathers more sleeked. The bird approaches the opponent with vigorous picking-up of the water surface or the muddy ground.

A.6.2.2. Irrelevant sticking: Comparable with sticking (in food intake postures). The bird sticks bill into water and behaves as if catching underwater prey.

A.6.2.3. Irrelevant ducking head (Fig. 6c): Comparable with ducking head (in food intake postures). The bird ducks the head into water and vigorously churns the bottom of the water.

A.6.2.4. Irrelevant dipping (Fig. 6d): Comparable with dipping the bill to catch small benthos (in food intake postures). Head kept lowest, trunk held fairly obliquely down.

With this posture the bird swings its head repeatedly, and rubs its bill lightly against the mud.

Irrelevant food intake, comparable with the food intake, and aroused during conflicts between territory owners and conspecific invaders at the territorial border, at driving an invader in walking, and at driving a heterospecific animal, e.g. Asian Wandering Tattler, Moorhen, Spotbill Duck, Teal and Blue-green Snake. 


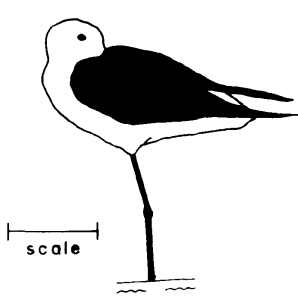

a $(A .6 .1$.

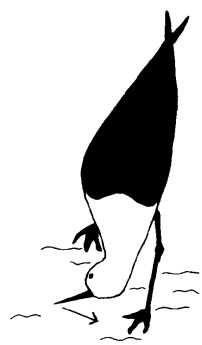

d $(A .6 .2 .4$.

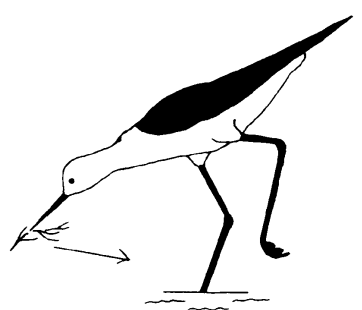

$\mathbf{g}(\mathrm{A} .6 .6$.

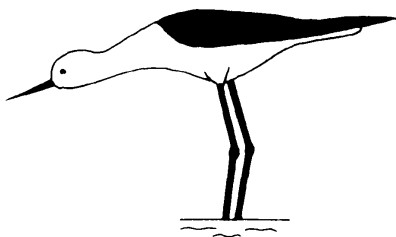

j (A.6.8.)

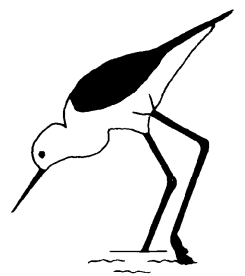

b $(A .6 .2 .1$.

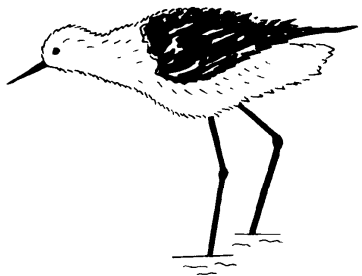

e (A.6.3.1.)

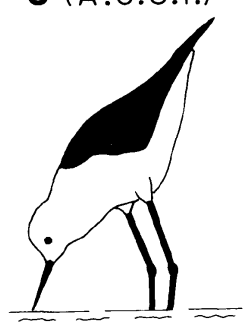

h $(A .6 .7$.

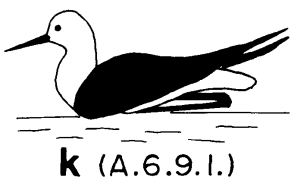

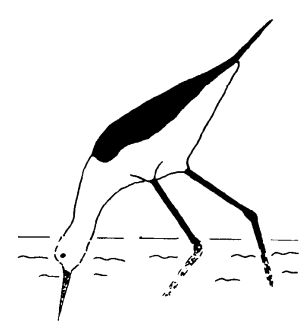

C (A.6.2.3.)

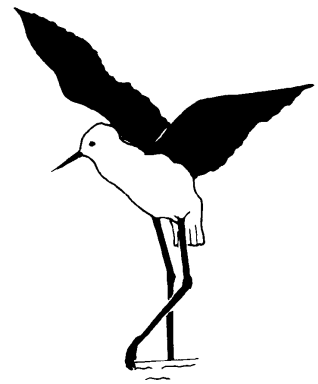

f $(A .6 .5$.

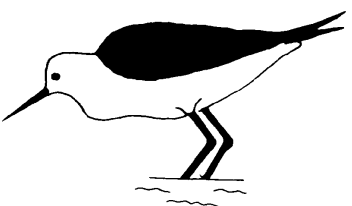

i (A.6.7.)

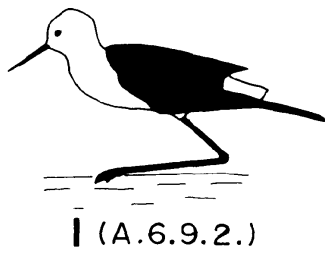

Fig. 6. Irrelevant postures. a, irrelevant sleeping; b, irrelevant picking up; c, irrelevant ducking head; d, irrelevant dipping; e, irrelevant body shaking; f, irrelevant wing flapping; $g$, irrelevant nesting; $h-i$, irrelevant splashing water; $j$, irrelevant neck extending; $k$, irrelevant sitting; 1 , irrelevant heel standing. (scale $-10 \mathrm{~cm}$ ).

A.6.3. Irrelevant shaking : Three types are distinguished.

A.6.3.1. Irrelevant body shaking (Fig. 6e): Comparable with body shaking (in comfort postures, unpubl.).

A.6.3.2. Irrelevant tail shaking: Comparable with tail shaking (in comfort postures). 
A.6.3.3. Irrelevant head shaking: Comparable with head shaking (in comfort postures).

Rarer than other irrelevant postures. It is difficult to distinguish these from the autochthonous postures. Irrelevant shaking is usually exhibited just after having driven a conspecific invader or during conflicts between territory owners and invaders at the territorial border. Once a bird exhibited irrelevant tail shaking after alert upright (A.1.4., Fig. $3 \mathrm{~g}-\mathrm{h}$ ) toward Common Pheasant which landed nearby.

A.6.4. Irrelevant preening: Identical to preening feathers (in comfort postures). Irrelevant shoulder preening, irrelevant belly preening, irrelevant breast preening, irrelevant side preening and irrelevant leg preening are distinguished.

In irrelevant preening the bill touches and actually preens feathers as in autochthonous preening but irrelevbant preening is performed more vigorously and ceases instantly. Various types of irrelevant preening are performed, sometimes preceded by repelling water (A.4.), or sometimes during bobbing head (A.1.1., Fig. 3a-b), usually by territory owners toward conspecific invaders, or reversely, and also at driving away heterospecific invaders such as Spotbill Duck, Teal and Little Egret.

A.6.5. Irrelevant wing flapping (Fig. 6f): Rarer than other irrelevant postures. Identical to wing flapping (in comfort postures), and difficult to distinguish from the autochthonous type, performed during conflicts between families, and by the bird to man.

A.6.6 Irrelevant nesting (Fig. 6g): Comparable with gathering nest materials (in nest building postures, unpubl.).

The bird pulls up withered grass from the ground or the water bottom and throws it aside or backward. Performance is more vigorous but only for a time shorter than in the autochthonous posture. This posture appears at intense conflicts between families or between territory owners and invaders in close proximity, sometimes during the performance of other agonistic behaviours. Once fluttering wings (A.9.2., Fig. 9d) preceded this posture.

A.6.7. Irrelevant splashing water (Fig. $6 \mathrm{~h}-\mathrm{i}$ ): Identical to splashing water (in copulation postures, unpubl.). Neck extended forward, trunk held fairly or a little obliquely down, head kept lowest, and followed by splashing the water surface fractionally with bill.

The intensely threatened or approached birds mostly exhibit this posture toward the opponent, sometimes preceded by repelling water (A.4.) or lowering head (A.3., Fig. 5). Although the autochthonous posture is performed only by females in copulation procedure, irrelevant splashing water is taken by both sexes of any ages, e.g. male to male, female to female, female to male, yearling to yearling.

A.6.8. Irrelevant neck extending (Fig. 6j): Identical to extending neck followed by splashing water (in copulation postures of female, unpubl.). Rarer than irrelevant splashing water (A.6.7, Fig. 6h-i).

When a territory pair and a conspecific invader were at territorial dispute, the female owner once took irrelevant neck extending nearby. After driving away a conspecific invader or at conflicts between families, a female sometimes invites the partner male to copulate with her, performing the autochthonous posture and actual copulation occasionally takes place. 
A.6.9. Irrelevant crouching: Two distinct types are recognized.

A.6.9.1. Irrelevant sitting (Fig. 6k): Comparable with sitting (in resting postures, unpubl.) or settling (in incubation postures, unpubl.). Occasionally accompanied by fluttering wings (A.9.2., Fig. 9c-e).

A.6.9.2. Irrelevant heel standing (Fig. 61): Similar to heel standing (in resting postures) or heel stand brooding (in parental care postures, unpubl.), but feathers sleeked. Occasionally accompanied by fluttering wings (A.9.2., Fig. 9c-e), and rarely also by one kind of aggressive calls "ki ki kyu-, ki ki kyu-...." (B.3.1.).

Irrelevant crouching is exhibited at intense conflicts between families, sometimes during the performance of body sleeked (A.1.3., Fig. 3d-f), lowering head (A.3., Fig. 5) and other postures. The bird occasionally performed irrelevant crouching in the water breast deep.

A.7. Attacking (Fig. 7): Eight distinct types are recognized. Although almost all attacking postures are exhibited by both sexes, actual pecking was done several times by only a particular male. Attacking occurs commonly at nesting territories, between territory owners and invaders and by territory owners toward other animals appearing within the territory, e.g. Coot, Moorhen, Spotbill Duck, Teal, Spotted Redshank, Greenshank, Long-billed Dowitcher, Grey Starling, Little Egret, Intermediate Egret, Little Ringed Plover, Blue-green Snake, Muskrat, man, etc.

A.7.1. Flying over head (Fig. 7a): Similar to head and legs down flight described by Hamilton (1975). Comparable with flying posture in a short distance flight (unpubl.). Legs dangled, neck extended downward, and head fairly lowered.

The bird flies up and flaps over, or sometimes hovers over the opponent for a while and lands nearby. This posture is usually repeated until withdrawal of the opponent.

A.7.2. Kicking head in flight (Fig. 7b): The bird kicks the head, the upper-neck or the back of the opponent.

Performed frequently during or after flying over head (A.7.1., Fig. 7a) or after or during offensive flight (A.7.5.6., Fig. 7g). After kicking, the bird lands near the opponent and sometines repeats the posture. The attacked bird sometimes performs bending down (A.8.3., Figs. 71, 8c).

A.7.3. Mounting opponent (Figs. 7c, 8b): Following kicking head in flight (A.7.2., Fig. 7b) or during flying over head (A.7.1., Fig. 7a), mounting opponent is sometimes performed. The bird rides on the back or the neck of the opponent, but gets off at once. The attacked bird sometimes performs bending down (A.8.3., Figs. 71, 8c).

A.7.4. Sinking under water: Usually performed after mounting opponent (A.7.3., Figs. 7c, 8b) at vigorous conflicts between families. The bird rides on the back or neck of the opponent and sinks it under the water. Several kinds of aggressive call (B.3.), e.g. "ki-kiki-, ki- kiki-", "kyuru-, kyuru-" or in yearling bird "pipipipi...", are accompanied by this posture. The attacked bird sometimes bends down for itself (A.8.3., Figs. 71, 8c).

A.7.5. Chasing: Eight types are distinguished.

A.7.5.1. Walking nearby: Identical to walking (in locomotion postures, unpubl.). During walking nearby the bird walks slowly toward the opponent, frequently together with irrelevant food intake (A.6.2.) and low pitched alarm call (B.1.1.) or ordinary alarm 


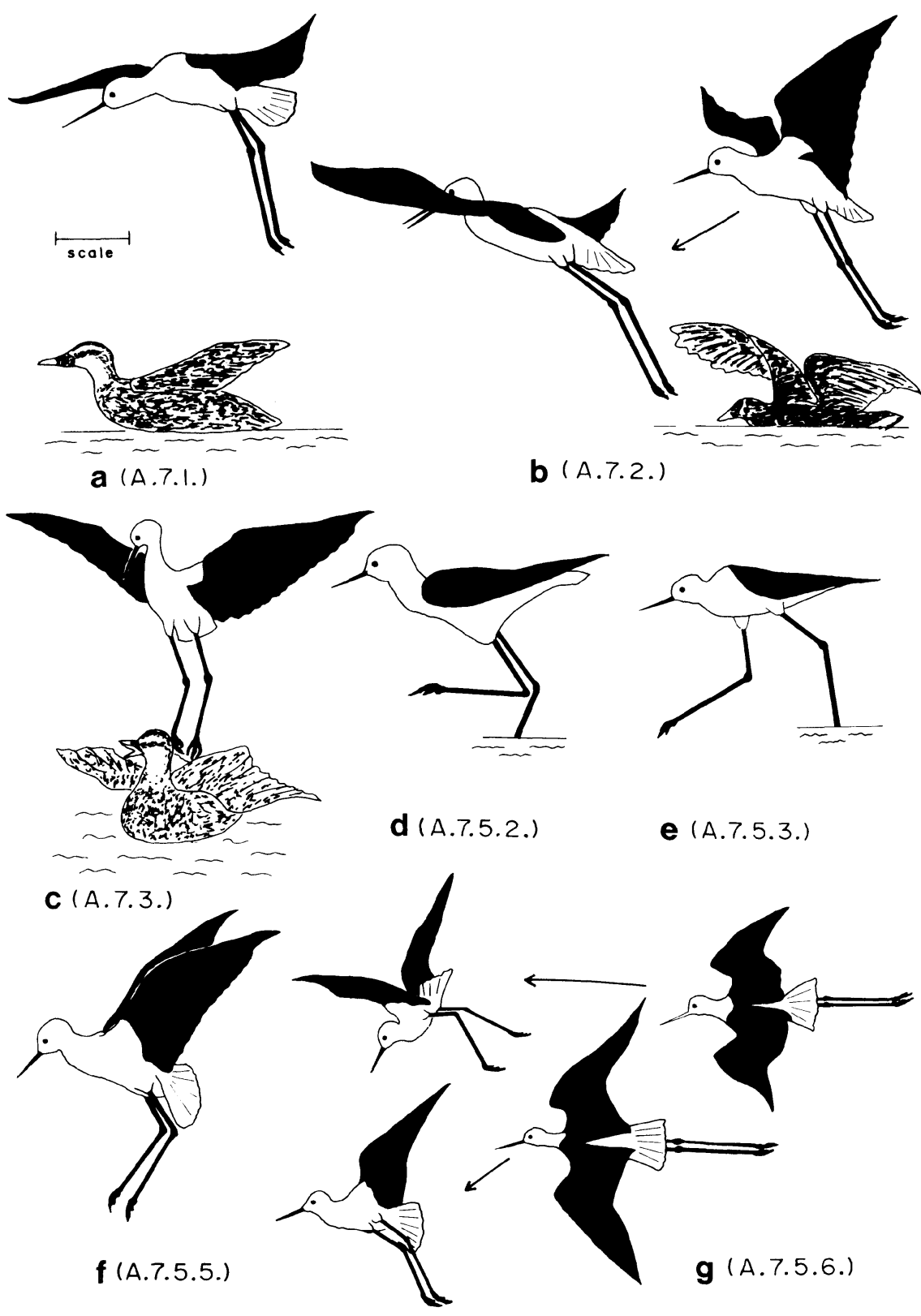




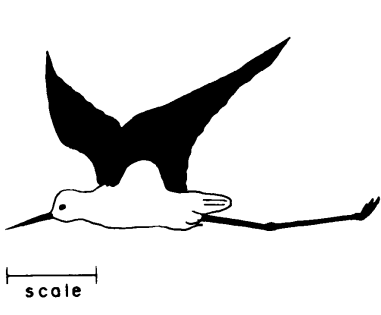

h $($ A.7.5.7.)

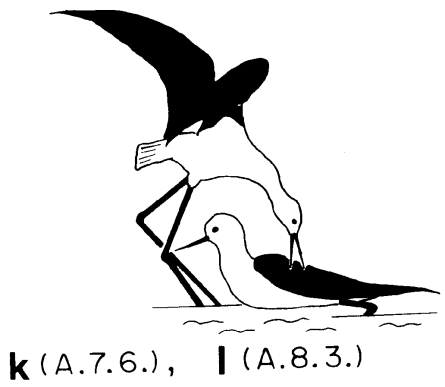

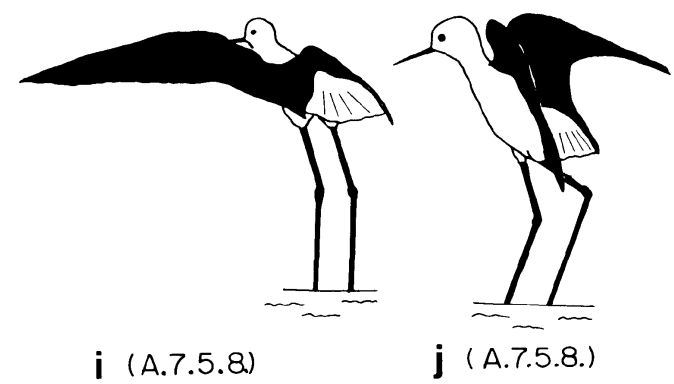

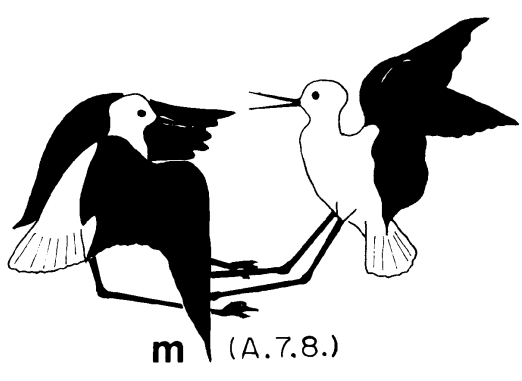

Fig. 7. Attacking postures. a, flying over head performed toward Spotbill Duck; b, kicking head in flight performed toward Moorhen; $\mathrm{c}$, mounting opponent performed toward spotbill duck; d, running toward. e, rushing; f, leaping up; $g$, offensive flight accompanied by pecking and kicking of upper bird toward lower one; $h, v$ shaped flight; $i-j$, opening and shutting wings; $\mathrm{k}$, biting; 1 , bending down; $\mathrm{m}$, kicking. (scale $=10 \mathrm{~cm}$ ).

call (B.1.2.).

A.7.5.2. Running toward (Fig. 7d): Comparable with body sleeked (A.1.3., Fig. 3df), but trunk held fairly horizontally. With this posture the bird runs toward the opponent.

A.7.5.3. Rushing (Fig. 7e): Similar to crouch-run described by Hamilton (1975). Neck retracted, bill and face pointed forward, and trunk held almost horizontally. With this posture the bird dashes toward the opponent.

A.7.5.4. Landing nearby: Identical to landing (in locomotion postures). In the incubating period or the parental care period, the territory owner who recognized the invader flies up quickly or performs offensive flight (A.7.5.6., Fig. 7g) and lands near it, sometimes followed by opening and shutting wings (A.7.5.8., Fig. 7i-j). The invader usually flees before or just after the owner's landing. If the invader does not flee, the owner performs landing nearby in succession.

A.7.5.5. Leaping up (Fig. 7f): The bird leaps up in the air several times. In case of conflict between conspecifics, leaping up is sometimes made before or during lowering head (A.3., Fig.5) or body sleeked (A.1.3., Fig. 3d-f) and followed by mutual kicking (A.7.8., Fig. $7 \mathrm{~m})$. Leaping up is rarely accompanied by call "pya pya pya...". 
A.7.5.6. Offensive flight (Fig. 7g): Similar to alerting flight (A.1.5., Fig. 3i-j), but neck and legs held more horizontally, wings bit vigorously, and usually accompanied by aggressive call (B.3.) "kye-kye-kye-kye-.....", or by high pitched alarm call (B.1.3.) "kikikikiki.....". When repulsing enemies such as Japanese Jungle Crow, Slaty-backed Gull and Black-tailed Gull, the bird flies up and rapidly pursuits the opponent, sometimes pecking (A.7.7.), kicking (A.7.8., Fig. 7m) or kicking head in flight (A.7.2., Fig. 7b) occurred during offensive flight.

The owner of the nesting territory made offensive fight against heterospecific invaders such as Little Ringed Plover, Kentish Plover, Moorhen and Spotbill Duck, or conspecific invaders, especially in the early phase of the parental care period. At the termination of offensive flight, landing nearby (A.7.5.4.) or opening and shutting wings (A.7.5.8., Fig. 7ij) occurred. Against the conspecific invaders, kicking head in flight (A.7.2., Fig. 7b) is occasionally performed. Then the attacker flies upward, and the attackee flies up in a moment, both making seesaw pursuit in performing kicking (A.7.8., Fig. $7 \mathrm{~m}$ ), pecking (A. 7.7.) or biting (A.7.6., Fig. 7k).

A.7.5.7. V shaped flight (Fig. 7h): Similar to dihedral wing flight display (Hamilton 1975). Wings held obliquely up in V shape.

Detecting conspecific invaders or other suspicious enemies such as Moorhen and Spotbill Duck in the nesting territory, the owner flies up and glides hurriedly to the opponent straightforward, keeping the same posture mentioned above. This posture is performed frequently in incubating or parental care period. The opponent flees or hides into reeds usually before the arrival of attacker. The attacker lands near the opponent and usually performs opening and shutting wings (A.7.5.8., Fig. 7i-j).

A.7.5.8. Opening and shutting wings (Fig. $7 \mathrm{i}-\mathrm{j}$ ): Usually performed at the final stage of running toward (A.7.5.2., Fig. 7d), rushing (A.7.5.3., Fig. 7e), landing after $v$ shaped flight (A.7.5.7., Fig. 7h), or sometimes at landing nearby (A.7.5.4.). The bird opens and shuts one wing or both quickly.

With this posture the bird chases down the opponent, usually Moorhen, in reeds. Leaning body (A.2., Fig. 4) or irrelevant picking up (A.6.2.1., Fig. 6b) rarely follows this posture.

A.7.6. Biting (Fig. 7k): Performed at vigorous combats between families, occasionally during or after mounting opponent (A.7.3., Figs. 7c, 8b) or sinking under water (A. 7.4.).

With bills opened birds bite in the head, wing, or tail sometimes mutually. Once a bird bit at a juvenile Spotbill Duck.

A.7.7. Pecking: Performed with bills closed, occurred sometimes during offensive flight (A.7.5.6., Fig. 7g), but actual pecking observed only several times, when the owner of a winter territory perceived a clay dicoy set within the territory. Irrelevant sleeping (A. 6.1., Fig. 6a) occurred just after pecking.

A.7.8. Kicking (Fig. $7 \mathrm{~m}$ ): Performed at conflicts between families, territory owners and invaders, and rarely between the owner and an invading Long-billed Dowitcher, usually accompanied by aggressive call (B.3.) and occasionally preceded by leaping up (A. 7.5.5., Fig. 7f) or leaning body (A.2., Fig. 4). This is also performed sometimes during 

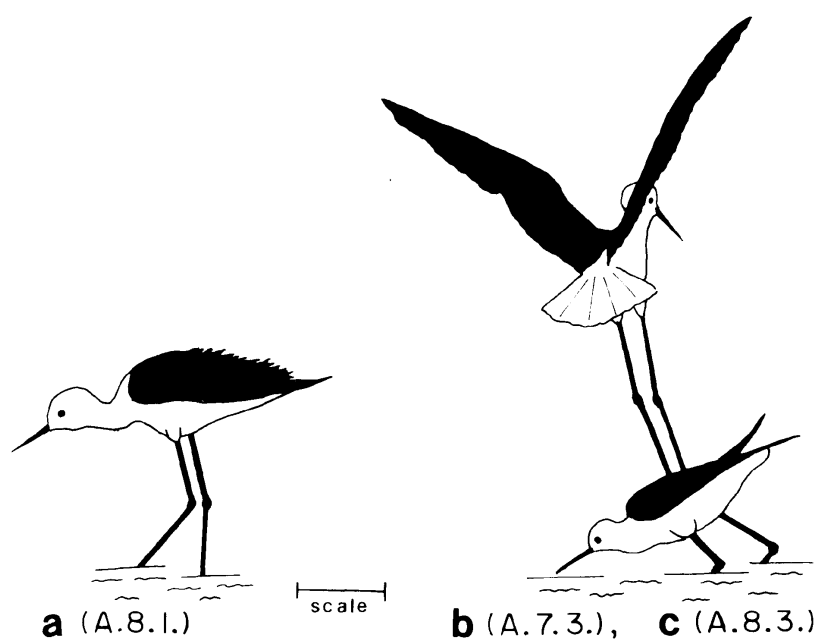

Fig. 8. Avoiding postures. a, submission; b, mounting opponent; $c$, bending down. (scale $=10$ $\mathrm{cm})$.

offensive flight (A.7.5.6., Fig. 7g).

A.8. Avoiding (Fig. 8): Six different types are recognized. Among those, lying down (A.8.4.) and concealing (A.8.5.) are performed only by chicks.

A.8.1. Submission (Fig. 8a): Head kept fairly low, neck retracted slightly, and feathers of mid back or rump ruffled and erected.

The volant juvenile bird sometimes performs submission when approaching the parent(s), or approached by parent(s) or by other dominant individuals. Although adults scarcely exhibit submission, the member of a pair rarely exhibits this posture each other, when both approach nearby, e.g. at alternation of incubation behaviour (unpubl.). Or a partner catching and nipping a large food animal makes this posture when approached by the other partner of the pair.

A.8.2. Escaping: The approached or threatened bird flees in jumping, walking, or light running for a short distance, rarely with subnission (A.8.1., Fig. 8a).

A.8.3. Bending down (Figs. 71, 8c): The bird attacked by kicking head in flight (A. 7.2., Fig. 7b), mounting opponent (A.7.3., Figs. 7c, 8b) or sinking under water (A.7.4.) often bends its legs and leans over.

A.8.4. Lying down: The early stage chick lies down on the ground stimulated by alarm call (B.1.) of parent(s).

When a human observer approaches chicks, they lie down in motionless until bodies are touched with his fingers.

A.8.5. Concealing: By alarm call (B.1.) of parent(s), not yet volant chicks of the later stage escape from the enemy in walking hurriedly or swimming toward the opposite shore, and conceal themselves among reeds or bushes.

Chicks performing concealing exhibit lying down toward a human observer, if approached. 
Table 3. Observed cases of avoiding postures caused by agonistic postures.

\begin{tabular}{|c|c|c|c|c|c|c|c|}
\hline & \multicolumn{7}{|c|}{ Avoiding } \\
\hline & $\begin{array}{l}\text { Submis- } \\
\text { sion }\end{array}$ & Escaping & $\begin{array}{l}\text { Bending } \\
\text { down }\end{array}$ & $\begin{array}{l}\text { Lying } \\
\text { down }\end{array}$ & Concealing & Fleeing & Totals \\
\hline Body sleeked & - & 3 & - & - & - & - & 3 \\
\hline Alert upright & - & 1 & - & - & - & - & 1 \\
\hline Leaning body & - & 1 & - & - & - & - & 1 \\
\hline Lowering head & - & 2 & - & - & - & 1 & 3 \\
\hline Repelling water & - & 1 & - & - & - & - & 1 \\
\hline Irrelevant picking up & - & 6 & - & - & - & 2 & 8 \\
\hline Irrelevant dipping & - & 1 & - & - & - & - & 1 \\
\hline Irrelevant preening & - & 1 & - & - & - & - & 1 \\
\hline Irrelevant nesting & - & 3 & - & - & - & 1 & 4 \\
\hline Flying over head & - & 3 & 2 & - & - & - & 5 \\
\hline Kicking head in flight & - & - & 3 & - & - & - & 3 \\
\hline Mounting opponent & - & - & 4 & - & - & 2 & 6 \\
\hline Sinking under water & - & - & 4 & - & - & - & 4 \\
\hline Walking nearby & 12 & 16 & - & - & - & 39 & 67 \\
\hline Running toward & 2 & 10 & - & - & - & 1 & 13 \\
\hline Rushing & 4 & 7 & - & - & - & 6 & 17 \\
\hline Landing nearby & - & 6 & - & - & - & 42 & 48 \\
\hline Offensive flight & - & 1 & - & - & - & 16 & 17 \\
\hline V shaped flight & - & 2 & - & - & - & - & 2 \\
\hline Ordinary alarm call & - & - & - & 3 & 4 & - & 7 \\
\hline Totals & 18 & 64 & 13 & 3 & 4 & 110 & 212 \\
\hline
\end{tabular}

A.8.6. Fleeing: The invader usually flies away, just after approached or attacked by the owner of the territory or dominant individuals, but sometimes takes off and flees soon before the owner's access. Birds approached suddenly by a man or threatened by other enemies such as Marsh Harrier, Black-eared Kite and crows, occasionaly take off and perform alerting flight (A.1.3., Fig. 3i-j), but they sometimes flied away.

The bird flees against dangerous animals such as crows, raptores and man, but rarely exhibits other avoiding postures against heterospecific animals. Table 3 shows the postures which elicited avoiding postures at conflicts between families, or territorial owners and invaders.

A.9. Diversionary display (Fig. 9): Two types, exhibited by both sexes, are distinguished.

A.9.1. Opening and closing wings (Fig. 9a-b): Opening and closing one wing or both more slowly and continuously than in opening and shutting wings (A.7.5.8., Fig. 7i-j) in attacking (A.7.). Exhibited at invasion of other animals or conspecifics into the territory, or just before driving away conspecific or heterospecific invaders such as Spotbill Duck, or around a human observer. The bird sometimes utters low calls sounding "gyu- gyugyu-......" or "gye- gye- gye-...".

A.9.2. Fluttering wings (Fig. 9c-e): The bird stands and opens one wing or both either fully or partly, and flutters in standstill. Performed more frequently than opening 


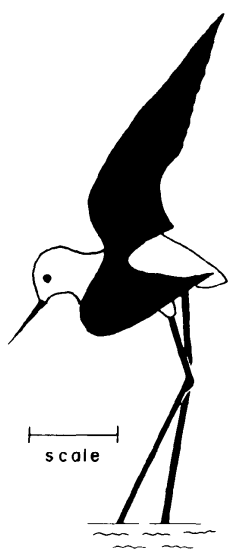

a $(A .9 .1$ )

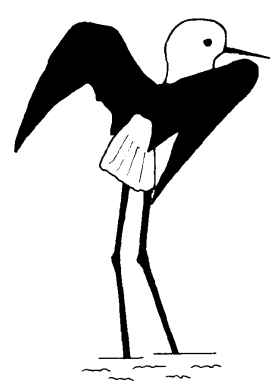

b (A.9.1.)

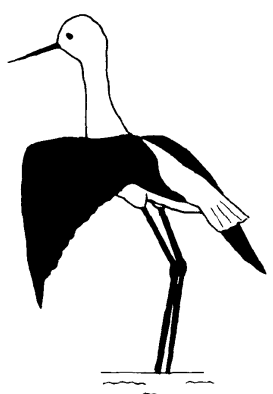

C (A.9.2.)
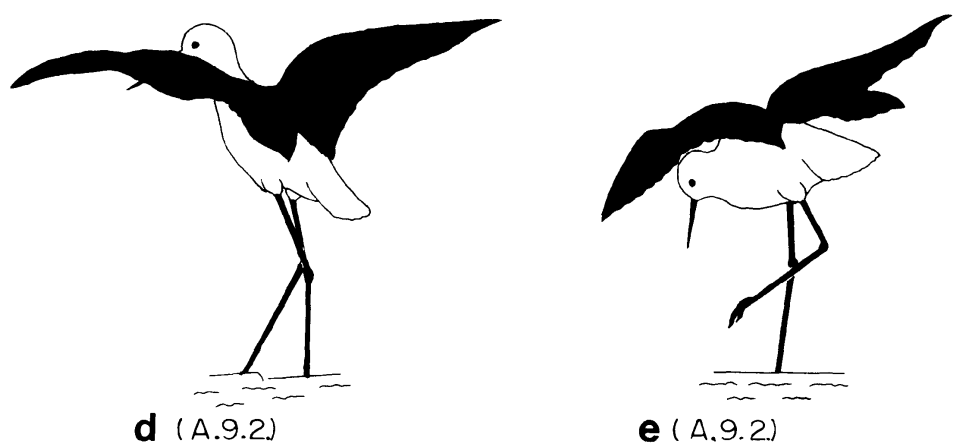

Fig. 9. Diversionary displays. $a-b$, opening and closing wings; $c-e$, fluttering wings. (scale $=10$ $\mathrm{cm})$.

and closing wings (A.9.1., Fig. 9a-b) and sometimes made during irrelevant crouching (A. 6.9., Fig. 6k-1) or occasionally accompanied by irrelevant picking up (Fig. 9b). Probably same to wing-flagging and extended wing display (Hamilton 1975), but exhibited rather during conflicts between families than toward approaching man, sometimes accompanied or preceded by call "gye-gye-gye-...".

\section{B. Calls}

B.1. Alarm call: According to the intensity, three types are recognized.

B.1.1. Low pitched alarm call: One note/s, "ki, ki, ki, ki,....". This appears at low intensity alerting, e.g. approach of an invader to the territory, or followed to ordinary alarm call (B.1.2.).

B.1.2. Ordinary alarm call: Two notes/s, "ki ki, ki ki, ki ki,....". Appearing at high intensity alerting such as before driving away conspecific invaders and other animals such as Spotbill Duck, Moorhen, Greenshank and crows. 
B.1.3. High pitched alarm call: More than three notes/s, "kikikikikiki.....". Uttered at alerting of the highest intensity, as in case of driving away some dangerous animals such as Moorhen, crows and man invading within or over the nesting territory.

Alarm call is uttered frequently in breeding sites but rarely in overwintering sites, and usually accompanied by alert (A.1.). As shown in Table 4, ordinary alarm call (B.1.2.) is mostly associated with walking nearby (A.7.5.1.) in chasing (A.7.5.), irrelevant food intake (A.6.2.), and offensive flight (A.7.5.6., Fig. 7g). Birds usually utter ordinary alarm call (B.1.2.) immediately after hetero- and conspecific invaders or enemies appear in nesting territories, sometimes preliminarily preceding to attacking (A.7.), irrelevant postures (A.6.) or diversionary display (A.9). When a human observer entered in the breeding site, birds behave equally as described above. Usually low pitched alarm call (B. 1.1.) follows ordinary alarm call (B.1.2.), if invaders go away from the nesting territories or an observer sits quietly or conceals in a blind. High pitched alarm call (B.1.3.) is well connected with specific postures such as alerting flight (A.1.5., Fig. 3i-j) and offensive flight (A7.5.6., Fig. 7g), so that is comparable with kye-call (B.3.4.) in aggressive call (B. 3.).

B.2. Snake alerting call: Soft and high call sounding "ku-ku-ku-......kukukukuku", "kikikikiki", "gugugugu", and "gugu gugu gugu ....".

This call is heard only when chasing a snake swimming across the nesting territory, and is usually accompanied by body sleeked (A.1.3., Fig. 3d-f), alert upright (A.1.4., Fig. $3 \mathrm{~g}-\mathrm{h}$ ) or walking nearby (A.7.5.1.), sometimes interposed by flying over head (A.7.1., Fig. 7a), kicking head in flight (A.7.2., Fig. 7b), leaping up (A.7.5.5., Fig. 7f), and landing nearby (A.7.5.4.). When one individual utters snake alerting call, the partner of the bird and neighbouring families usually join together.

B.3. Aggressive call: Six types are recognized.

B.3.1. $k i k i k y u-$, or $k i k i k i k y u$-call: Produced at conflicts among families or individuals on the territorial border, and occasionally connected with irrelevant crouching (A.6.9., Fig. 6k-1).

B.3.2. $k i-k i k i-c a l l$ : Produced at more vigorous fighting between families than $k i k i$ kyu-call (B.3.1.) and accompanied by leaping up (A.7.5.5., Fig. 7f), mounting opponent (A.7.3., Figs. 7c, 8b), sinking under water (A.7.4.), rarely interposed by kicking (A.7.8., Fig. $7 \mathrm{~m})$.

B.3.3. kue- call: At fighting between families, observers or family members not concerned actual fighting utter this call repeatedly, "kue-, kue-,......", which sounds as if scoffing.

B.3.4. kye- or kyu-call: The bird utters this slightly wobbled call repeatedly, "kye-, kye-, ....." or "kyu-, kyu-,.....", when pursuing enemies such as crows and Slaty-backed Gull in the air, or when nose-diving toward enemies such as a cat and a man on the ground, also when making alerting flight (A.1.5., Fig. $3 \mathrm{i}-\mathrm{j}$ ) or offensive flight (A.7.5.6., Fig. $7 \mathrm{~g})$.

B.3.5. kyuru-call: Produced repeatedly "kyuru-, kyuru-,....." at conflicts between families, or at flying back from nose-diving to an enemy on the ground.

B.3.6. pya call: With several notes as "pya, pya, pya,...", rarely connected with 


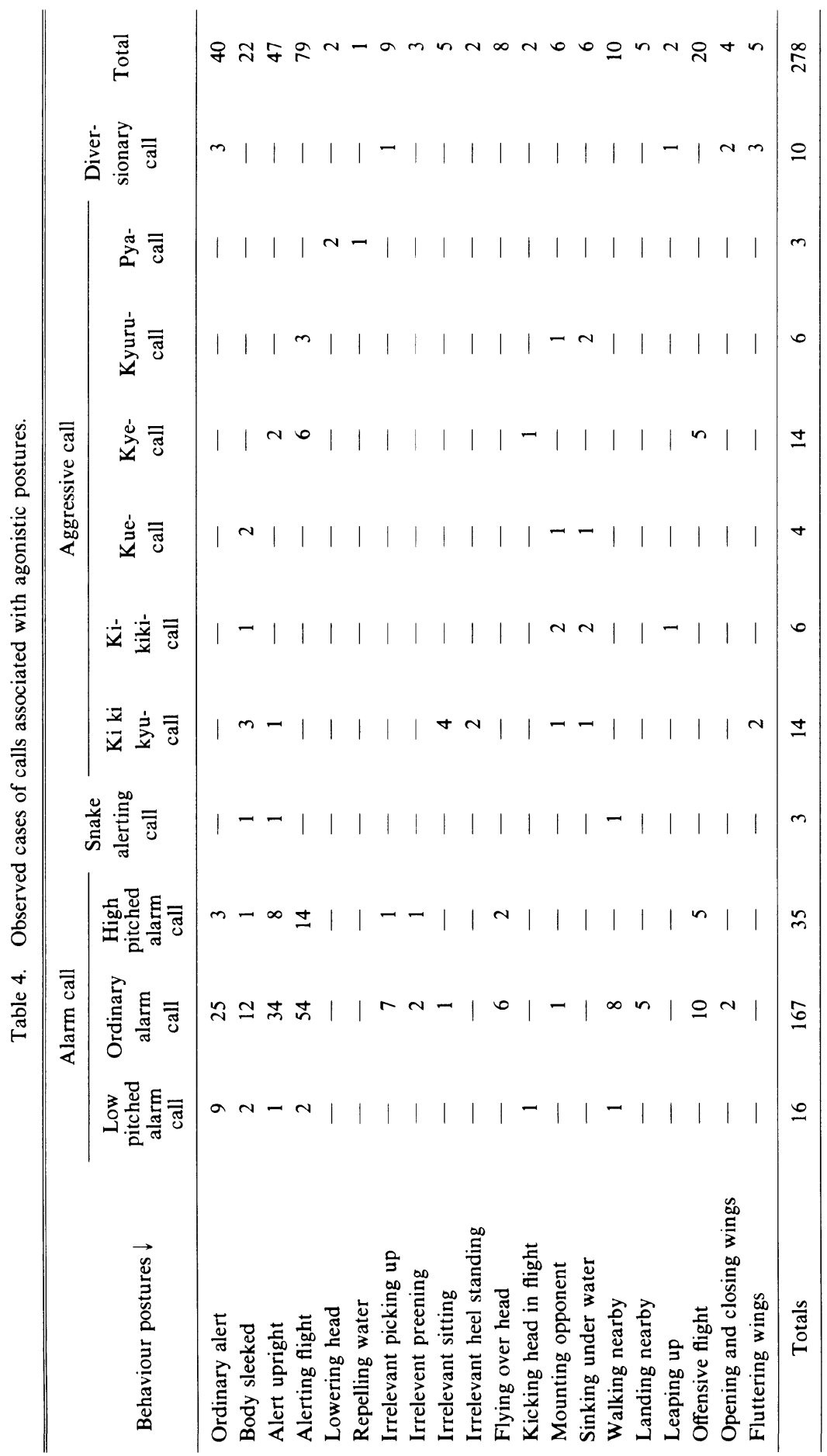


leaping up (A.7.5.5., Fig. 7f) or lowering head (A.3., Fig. 5).

Although exhibited at combats between families or repulsing enemies, those types of aggressive call are uttered each at defferent situation, each connected each with specific postures (Table 4).

Until the change of call, juveniles utter identical calls sounding "pi, pi, pi, pi....", even at different situations at which adults elicit ki ki kyu-call (B.3.1.), ki-kiki- call (B.3.2.), kue- call (B.3.3.) or kyuru- call (B.3.5.).

B.4. Diversionary call: Low and soft call sounding "gye, gye, gye, ...." or "gue, gue, gue, ....".

In the parental care period parent(s) uttered this call on the ground to divert attention of the human observer from the nest or chicks, sometimes associated with opening and closing wings (A.9.1., Fig. 9a-b) and fluttering wings (A.9.2., Fig. 9c-e, Table 4).

\section{Acknowledgements}

I wish to express my sincere gratitude to Professor S. F. Sakagami, Hokkaido University, for his kind and pertinent guidance and critical reading of the typescript, to Professor S. Yamagishi and Dr. T. Kawamichi, Osaka City University for their encouragement and advices, to Mr. K. Fujisaki, the Principal of Ichikawa High School, for his generous support throughout the work, and to Mr. and Mrs. Hasuo, Gyotoku Bird Observatory, who helped me in various ways. I also express my cordial thanks to Mr. G. Hishinuma and to all other members of the staff of the Shinhama Imperial Preserve for their help offered to my study.

\section{References}

Bannerman, D. A. 1961. The birds of the British Isles. 10: 275-286.

Cramp, S. and K. E. L. Simmons. 1983. Handbook of the birds of Europe, the Middle East and North Africa. volume III. Waders to Gulls. 913 pp., London.

Glutz von Blotzheim, U. N., K. M. Bauer and E. Bezzel. 1977. Handbuch der Vögel Mitteleuropas 7. Charadriformes. 893 pp., London.

Goriup, P. D. 1982. Behaviour of Black-winged Stilts. Brit. Birds 75: 12-24.

Hamilton, R. B. 1975. Comparative behavior of the American Avocet and the Black-winged Stilt (Recurvirostridae). Ornith. monogr. No. 17. vi $+98 \mathrm{pp}$.

Hasuo, J. 1982. The diary at Gyotoku Bird Observatory. Chikuma Shonen Library 61. 214 pp., Tokyo. (In Japanese.)

Kunimatsu, T. 1979. The Black-winged Stilt flies in the sky. Kodomo Kagaku Tosho. 35 pp., Tokyo. (In Japanese.)

Staton, J. 1945. The breeding of Black-winged Stilts in Nottinghamshire in 1945. Brit. Birds 38: 322-328.

Witherby, H. F., F. C. R. Jourdain, N. F. Ticehurst and B. W. Tucker. 1940. The handbook of British Birds 4. 398pp., London. 


\section{セイタカシギの行動社会学的研究}

\section{I. 敵対行動}

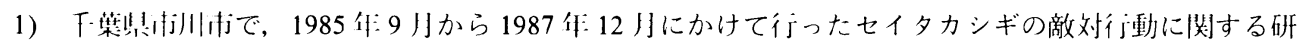
究結果を述へた。

2) 敵対行動は行動姿勢と南に分けて記述した。

3）敵対姿勢は问種または基種湖体との関係で生じるもので，1. 警戌姿勢，2．傾斜姿勢，3. 低韻姿

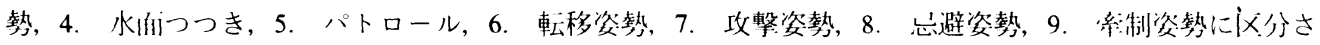
れた。

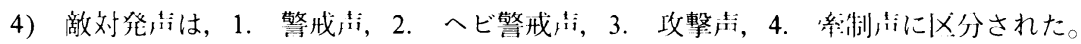

5)これらの行動姿勢と南が代じる状況も併せて述べた。

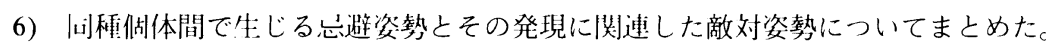

7) 各敵対発声と関連して牲じる行動姿勢について述べた。

北川珠樹：抽川高校，画272 打川市東菅野 4-1-1 